\title{
A Culture-Independent PCR-Based Assay to Detect the Root Rot Pathogen Fusarium solani Species Complex 11 from Soybean Roots and Soil
}

Periasamy Chitrampalam, Nivi Abraham, and Berlin D. Nelson, Jr., ${ }^{\dagger}$ Department of Plant Pathology, North Dakota State University, Fargo 58108

\begin{abstract}
Fusarium solani species complex (FSSC) 11 is the primary phylogenetic species of FSSC causing root rot in soybean in the north-central United States. A polymerase chain reaction (PCR)-based assay was developed to identify and differentiate FSSC 11 from the less aggressive FSSC 5 and other Fusarium and Pythium spp. associated with soybean roots. The primer set FSSC11-F and FSSC11-R designed from the RNA polymerase second largest subunit gene yielded the expected amplicon of about 900 bp with DNA from all 22 FSSC 11 isolates tested in PCR. However, it did not produce an amplicon with DNA from 29 isolates of FSSC 5, seven other Fusarium spp., three Pythium spp., and soybean tested in

PCR. Furthermore, the primer set successfully detected FSSC 11 from a DNA mixture containing the DNA of FSSC 11, FSSC 5, other Fusarium spp., and soybean. The primer set also detected FSSC 11 from both soil and soybean roots. Additionally, the prevalence of FSSC 11 in soybean roots was determined in five fields in North Dakota by both a culture-independent PCR approach with FSSC11-F and FSSC11-R and a culture-dependent approach. Results from both the culture-dependent and culture-independent approaches with FSSC11-F and FSSC11-R were consistent and revealed the presence of the FSSC 11 in three of five fields sampled.
\end{abstract}

Fusarium root rot is one of the primary threats to soybean production in the United States. The annual loss from this disease was estimated to be 8.3 million bushels in 2009 (Koenning and Wrather 2010). More than 15 Fusarium spp. such as Fusarium oxysporum species complex (FOSC), F. solani species complex (FSSC), F. tricinctum species complex (FTSC), $F$. avenaceum, $F$. incarnatumequiseti species complex (FIESC), $F$. graminearum, $F$. proliferatum, $F$. pseudograminearum, $F$. redolens, $F$. semitectum, and $F$. sporotrichioides have been frequently isolated from soybean roots and implicated in causing root rot (Diaz Arias et al. 2013a; Meyer et al. 2010; Rupe et al. 2010; Zhang et al. 2010). Members of the FSSC are one of the top two predominant species associated with soybean root rot in the United States, including the Red River Valley of North Dakota and Minnesota, the most northern soybean production area (Chitrampalam and Nelson 2016; Diaz Arias et al. 2013a,b; Nelson et al. 1997).

Because multiple Fusarium spp. are capable of causing root rot in soybean, with similar symptoms of slow emergence coupled with brown to dark-brown lesions on the roots or decay of the entire tap root, it is very difficult to determine which species is responsible for the root rot observed in a particular field based on symptoms alone. Identification of the species usually requires isolation, purification, and confirmation based on either taxonomic characters or DNA sequence-based methods. DNA sequence-based identification of the species requires DNA extraction from pure culture, polymerase chain reaction (PCR) amplification of the internal transcribed spacer (ITS) region or portions of the elongation factor 1- $\alpha(E F 1-\alpha)$ gene, and sequencing coupled with blastn search at the National Center for Biotechnology Information (NCBI) GenBank or FUSARIUM-ID. However, both culture- and DNA sequence-based methods of identification require considerable time and numerous steps. Therefore, a quick culture-independent approach would be useful to quickly identify the species causing root rot in a particular soybean

${ }^{\dagger}$ Corresponding author: B. D. Nelson, Jr.; E-mail: berlin.nelson@ndsu.edu

Current address of P. Chitrampalam: Department of Research and Development, Eurofins Biodiagnostics, Longmont, CO 80504.

*The $\boldsymbol{e}$-Xtra logo stands for "electronic extra" and indicates that four supplementary figures and two supplementary tables are published online.

Accepted for publication 29 August 2017.

C 2018 The American Phytopathological Society production field. Nucleic acid-based methods such as PCR and realtime PCR (qPCR) assays with target-specific primers and DNA arrays with target-specific probes are widely used to specifically detect a species of interest directly from plant tissue and soil (Chen et al. 1999; Fan et al. 2015; Hong et al. 2010; Lievens and Thomma 2005; Wang et al. 2013). For example, a PCR-based assay has been developed to specifically detect $F$. virguliforme, a causal agent of sudden death syndrome, from both soybean roots and soil (Li and Hartman 2003). However, no such PCRbased assay is currently available to specifically detect members of the FSSC that cause root rot in soybean.

FSSC consists of three clades (1,2 and 3) with over 40 phylogenetic species (O'Donnell 2000; O'Donnell et al. 2008). Clade 1 consists of two species, F. illudens and Nectria plagianthi from New Zealand, while clade 2 consists of at least eight phylogenetic species, including $F$. virguliforme and $F$. tucumaniae, causal agents of sudden death syndrome in soybean. However, clade 3 is the most common, largest, and diverse clade, which includes most of the FSSC species associated with soil and plants (Nalim et al. 2011; O'Donnell 2000; O'Donnell et al. 2008). The FSSC that causes root rot in soybean is also included in clade 3 but it is unknown how many phylogenetic species of FSSC are associated with soybean roots and which one is predominantly causing root rot in soybean in the United States. Recently Chitrampalam and Nelson (2016) reported that two phylogenetic species, FSSC 5 and FSSC 11 belonging to clade 3 , have been predominantly associated with soybean roots in North Dakota and Minnesota. FSSC 11 was the most aggressive and primary species causing root rot in soybean, whereas FSSC 5 was less aggressive to nonpathogenic, and may not be a serious threat to soybean cultivation under the prevailing environmental conditions in that area (Chitrampalam and Nelson 2016). However, isolates of FSSC 5 are also commonly associated with soybean roots along with the aggressive isolates of FSSC 11, and they are difficult to differentiate based on morphology alone. Therefore, a PCR-based assay is necessary to precisely differentiate FSSC 11 not only from FSSC 5 but also from other Fusarium and Pythium spp. that are commonly associated with soybean roots (Diaz Arias et al. 2013a,b; Nelson and Windels 1992; Rupe et al. 2010; Zhang et al. 2006; Zitnick-Anderson and Nelson 2015). The objective of this study was to develop PCR primers specific to FSSC 11 and subsequently determine their specificity, sensitivity, and reliability in identifying FSSC 11 directly from soybean roots and soil.

\section{Materials and Methods}

Primer design. The RNA polymerase second large subunit 2 (RPB2) gene sequence was used for designing primers specific for 
FSSC 11. The RPB2 sequences of both FSSC 11and FSSC 5 were obtained from the previous FSSC study (Chitrampalam and Nelson 2016), whereas RPB2 sequences of other Fusarium spp. were obtained from GenBank. Sequences from all species were multiple aligned using Bioedit v.5 (Ibis Biosciences, Carlsbad, CA), and FSSC 11-specific primers were designed manually from the region conserved $(100 \%)$ among FSSC 11 isolates; however, that region varied for FSSC 5 and other Fusarium spp. (Supplementary Fig. S1). In total, three primer pairs were designed and tested for their specificity to FSSC 11. These primers were also tested in silico against representative sequences from more than 25 agriculturally and clinically important phylogenetic species in clade 3 (O'Donnell 2000; Zhang et al. 2006) to further confirm their specificity to FSSC 11 (data not shown).

Primer specificity. The specificity of the designed primer set to FSSC 11 was determined by testing their cross reactivity against FSSC 5 and other Fusarium spp. such as FTSC, F. acuminatum, $F$. graminearum, $F$. proliferatum, FIESC, FOSC, and $F$. virguliforme in PCR. The cross reactivity of the FSSC 11-specific primer set was also tested against three Pythium spp. from soybean: Pythium heterothalicum, P. ultimum, and P. perplexum. With the exception of DNA of FSSC 11 isolates from Minnesota and DNA of $F$. graminearum, all other DNA used in this study for FSSC 11, FSSC 5, other Fusarium spp., and Pythium spp. were obtained from the laboratory of Dr. Berlin Nelson, North Dakota State University (NDSU), Fargo, and these DNA were originally extracted from Fusarium and Pythium spp. isolated from soybean roots (Chitrampalam and Nelson 2016; Nelson et al. 1997; Zitnick-Anderson and Nelson 2015). DNA of F. graminearum was kindly provided by Dr. Brueggeman, NDSU, Fargo. The FSSC 11 isolates and $F$. virguliforme isolates from Minnesota were provided by Dr. Malvick, University of Minnesota, and all other $F$. virguliforme isolates tested in this study were provided by Dr. Leandro, Iowa State University, Ames. DNA from these isolates was extracted using the DNeasy plant mini kit (Qiagen, Valencia, CA). The details of Fusarium and Pythium spp. used for testing primer specificity are listed in Supplementary Table S1.

PCR was performed in a $25-\mu 1$ reaction, and the reaction mixture contained $12.5 \mu \mathrm{l}$ of $2 \times$ GoTaq green mix (Promega Corp., Madison, WI), $1 \mu \mathrm{l}$ of each forward and reverse primer, $2 \mu \mathrm{l}$ of DNA $(10 \mathrm{ng} / \mu \mathrm{l})$, and $8.5 \mu \mathrm{l}$ of sterilized water. In total, three primer sets were tested for FSSC 11 specificity, and only the primer set FSSC11-F (forward) and FSSC11-R (reverse) was initially found to be specific to FSSC 11; therefore, only the FSSC11-F and FSSC11-R set was considered for further detailed validation. PCR cyclic parameters for FSSC11-F and FSSC11-R were initial denaturing at $95^{\circ} \mathrm{C}$ for $5 \mathrm{~min}$, followed by 40 cycles of denaturing at $95^{\circ} \mathrm{C}$ for $60 \mathrm{~s}$, annealing at $64^{\circ} \mathrm{C}$ for $45 \mathrm{~s}$, and extension at $72^{\circ} \mathrm{C}$ for $60 \mathrm{~s}$. A final extension was carried out at $72^{\circ} \mathrm{C}$ for $5 \mathrm{~min}$. PCR products $(8 \mu \mathrm{l})$ were separated on a $1 \%$ agarose gel containing gelred (Biotium, Inc., Fremont, CA) by electrophoresis and visualized under a UV transilluminator. Once the amplifications were confirmed on the gel, PCR products from five random samples were cleaned with exonuclease I and rAPid (alkaline phosphatase) by following the manufacturer's protocol (USB Products, Cleveland, $\mathrm{OH}$ ) and sequenced at the GenScript sequencing facility (GenScript USA Inc., Piscataway, NJ). PCR was also performed with primers ITS1 and ITS4 for every isolate tested to check the integrity of the DNA in PCR and also to make sure that the previous negative amplification of FSSC 5 and other Fusarium spp. with FSSC 11-specific primers was exclusively due to primer specificity. PCR was repeated a second time with five representative isolates each from FSSC 5 (91-47-3, 9179-1, 91-85-3, 91-104-2, and 95-5-1) and FSSC 11 (91-112-10, 91-743, 91-113-3, SVY-215-1, and SVY-386-1) and one isolate each from other Fusarium and Pythium spp. used in this study.

Detection of FSSC 11 in the presence of soybean DNA. The feasibility of the primer set FSSC11-F and FSSC11-R to detect FSSC 11 in the presence of soybean DNA was determined by testing the primer set with a DNA mixture created manually by mixing both FSSC 11 DNA (isolate 91-113-3) and soybean DNA. A series of PCR was performed, with one concentration of FSSC 11 DNA mixed with a series of concentrations of soybean DNA. The PCR was performed in a $25-\mu$ l reaction, and the PCR mixture contained $12.5 \mu \mathrm{l}$ of
GoTaq mix; $1 \mu \mathrm{l}$ of each forward and reverse primer; $20 \mathrm{ng}$ of FSSC 11 DNA mixed with soybean DNA at either $0,20,200,2,000$, or $20,000 \mathrm{ng}$; and double-distilled (dd) $\mathrm{H}_{2} \mathrm{O}$ to $25 \mu \mathrm{l}$. PCR without DNA served as a negative control. The PCR conditions and subsequent gel electrophoresis to confirm amplification was performed as described in the previous section.

Detection of FSSC 11 in the presence of FSSC 5 and other Fusarium spp. The efficiency of the primer set FSSC11-F and FSSC11-R to detect FSSC 11 in the presence of FSSC 5 and other Fusarium spp. was determined by testing the primer set with a DNA mixture containing DNA of FSSC 11 (91-113-3), FSSC 5 (91-47-3), or other Fusarium spp. in PCR. The following 10 PCR were performed with DNA either from individual species or from multiple Fusarium spp. in different combinations: $1=$ FSSC 11 (20 ng), 2 = FSSC 5 $(20 \mathrm{ng}), 3=$ FOSC $(20 \mathrm{ng}), 4$ = FTSC $(20 \mathrm{ng}), 5=$ soybean $(20 \mathrm{ng})$, $6=$ FSSC $11(10 \mathrm{ng})+$ FSSC $5(10 \mathrm{ng}), 7=$ FSSC $11(10 \mathrm{ng})+$ FOSC $(10 \mathrm{ng}), 8=\mathrm{FSSC} 11(10 \mathrm{ng})+\mathrm{FTSC}(10 \mathrm{ng}), 9=\mathrm{FSSC} 11(10 \mathrm{ng})+$ soybean (10 ng), and 10: FSSC 11 (10 ng) + FSSC 5 (10 ng) + FOSC $(10 \mathrm{ng})+$ FTSC $(10 \mathrm{ng})+$ soybean $(10 \mathrm{ng})$. The PCR was performed in a $25-\mu l$ reaction, and the PCR mixture contained $12.5 \mu$ l of GoTaq mix, $1 \mu l$ of each forward and reverse primer, DNA either from a single species or multiple species depending on the treatment, and $\mathrm{ddH}_{2} \mathrm{O}$ to $25 \mu \mathrm{l}$. A PCR without a DNA template was used as a negative control. The PCR conditions and subsequent gel electrophoresis to confirm amplification were performed as described previously.

DNA concentration detection limit. In order to determine the minimum DNA concentration required for FSSC 11-specific primer set FSSC11-F and FSSC11-R to successfully detect the FSSC 11 in $\mathrm{PCR}$, nine PCR assays were conducted with different concentration of FSSC 11 DNA (91-113-3). The DNA concentrations tested were $100 \mathrm{ng}, 10 \mathrm{ng}, 1 \mathrm{ng}, 100 \mathrm{pg}, 10 \mathrm{pg}, 1 \mathrm{pg}, 100 \mathrm{fg}, 10 \mathrm{fg}$, and $1 \mathrm{fg}$ per PCR. The PCR without a DNA template served as the negative control. The PCR was performed in a $25-\mu 1$ reaction, and the PCR amplifications were checked as described above. This experiment was repeated.

Detection of FSSC 11 directly from the root independent of isolation. The potential of the primer set FSSC11-F and FSSC11$\mathrm{R}$ to detect FSSC 11 directly from root tissue independent of isolation was determined. Four known FSSC 11 isolates (91-113-3, 91-112-10, SVY-215-1, and SVY-386-1) were included in this experiment. Soybean seed (cultivar Barnes) were surface disinfected with $10 \%$ bleach for $1 \mathrm{~min}$ and washed twice with sterilized water. One surface-disinfected seed was placed on top of the potting mix in cone-tainers (type SC10 super cell, 164-ml volume; Stuewe and Sons, Inc., Corvallis, OR) filled with pasteurized potting mix consisting of pasteurized Glyndon sandy loam, peat moss, and vermiculite $(1: 1: 1, \mathrm{vol} / \mathrm{vol} / \mathrm{vol})$. A spore suspension $\left(1 \mathrm{ml}\right.$ at $2 \times 10^{6}$ macroconidia/ml $)$ prepared from a 2 week old culture on PDA was placed on top of the seed and the seed was then covered with $1 \mathrm{~cm}$ of potting mix and watered regularly. Seed planted without fungus served as the noninoculated control. There were two replications for each isolate, and they were arranged arbitrarily in cone-tainer racks and placed in a greenhouse. Greenhouse temperatures ranged from 23 to $25^{\circ} \mathrm{C}$ and plants were illuminated for $16 \mathrm{~h} /$ day with natural light and high-pressure sodium lamps $\left(1,000 \mu \mathrm{E} \mathrm{m}^{-2} \mathrm{~s}^{-1}\right)$. After a 5-week incubation, the roots from each plant were washed in running tap water, and a $2-\mathrm{cm}$ section of the upper part of the tap root showing a brown lesion was excised, surface disinfected with $10 \%$ bleach for $1 \mathrm{~min}$, washed with sterilized water twice, placed in a 2-ml centrifuge tube, and lyophilized. These samples were stored at $4^{\circ} \mathrm{C}$ until used for DNA extraction.

DNA was extracted from each lyophilized root sample using a DNeasy plant mini kit (Qiagen). Two PCR were performed for each sample, one with FSSC 11-specific primers (FSSC11-F and FSSC11R) and another with ITS primers (ITS1 and ITS4). PCR with the FSSC 11 -specific primer set was performed in a $25-\mu 1$ reaction as described above, with the addition of bovine serum albumin (BSA; $0.5 \mu \mathrm{g}$ per 25- $\mu$ l PCR). PCR conditions for the ITS primer were $94^{\circ} \mathrm{C}$ for $1 \mathrm{~min}$; 40 cycles at $94^{\circ} \mathrm{C}$ for $1 \mathrm{~min}, 55^{\circ} \mathrm{C}$ for $30 \mathrm{~s}$, and $72^{\circ} \mathrm{C}$ for $1 \mathrm{~min}$; and a final extension of $72^{\circ} \mathrm{C}$ for $5 \mathrm{~min}$. PCR with DNA extracted from a pure culture of FSSC 11 (91-113-3) served as positive control, and autoclaved water served as a negative control. The PCR amplifications were 
evaluated on an agarose gel, and the PCR products from positive amplifications were sequenced and compared with the $R P B 2$ sequence of the reference FSSC 11 isolate (91-113-3) to confirm the FSSC 11-specific amplification.

Detection of FSSC 11 from field samples. To determine the suitability of FSSC11-F and FSSC11-R in a field survey to estimate the prevalence of FSSC 11 root rot in soybean production fields, root samples were collected from fields and assayed for FSSC 11 by both a culture-independent PCR-based assay with FSSC11-F and FSSC11-R and a culture-based assay.

Soybean seedlings were collected from five fields in June 2015 in North Dakota. In each field, 10 seedlings showing symptoms of root rot such as slow emergence, yellowing, and wilting were collected randomly across the field and placed in a polyethylene bag for immediate transport to the laboratory. These seedlings were either processed immediately or stored at $4^{\circ} \mathrm{C}$ until processed. The roots from each seedling were excised and thoroughly washed in running tap water to remove the soil debris. Then, each root sample was surface disinfected with $10 \%$ bleach for $1 \mathrm{~min}$, washed in sterilized water twice, patted dry with autoclaved paper towels, and cut into four 1-cm-long pieces. Two pieces were used for Fusarium sp. isolation and two were used for DNA extraction.

Two root pieces from each sample were ground using liquid nitrogen, and DNA was extracted from the ground sample using the DNeasy plant mini kit (Qiagen) and stored at $-20^{\circ} \mathrm{C}$. Two PCR were performed for each sample, one with FSSC 11-specific primers (FSSC11-F and FSSC11-R) and another one with ITS primers (ITS1 and ITS4) with additions of BSA, as described above. The PCR amplifications were evaluated on $1 \%$ agarose gel, and the PCR products from positive amplifications were sequenced and compared with the $R P B 2$ sequence of reference isolate 91-113-3 to confirm FSSC 11-specific amplification. A positive check consisting of DNA extracted from roots artificially inoculated with FSSC 11 was used in this experiment.

The remaining two surface-disinfected root pieces from each sample were plated on Nash-Snyder medium (Nash and Snyder 1962) and incubated at room temperature for 2 to 3 days. The hypha emerging from root pieces were hyphal tipped and transferred individually to PDA amended with streptomycin $(33 \mathrm{mg} / \mathrm{ml})$ and incubated for 10 to 12 days in a 12-h cycle of light and darkness at room temperature. Each isolate was then pure cultured by single-spore isolation on PDA, and macroconidia from each pure culture were stored in $30 \%$ glycerol at $-80^{\circ} \mathrm{C}$. Each Fusarium isolate was then identified to species by DNA sequencing. Briefly, each isolate from cryogenic storage was plated on PDA and incubated at room temperature for 2 weeks; then, mycelia were collected and used for DNA extraction. Two loci were PCR amplified for each isolate: the ITS region plus the D1 and D2 domains of the nuclear large-subunit of ribosomal DNA with primer sets ITS5 and NL4, and a portion of EF1- $\alpha$ with primer sets EF1 and EF2 (O' Donnell 2000). The PCR conditions for each primer set were followed as described by O' Donnell (2000). The cleaned PCR products were sequenced in both directions at the GenScript sequencing facility (GenScript USA Inc.). The final consensus sequences from each isolate were searched (blastn) in both the NCBI GenBank and FUSARIUM-ID databases to identify the species. However, searching of sequences from 10 isolates revealed 99 to $100 \%$ identity to both $F$. acuminatum and FTSC in both databases. Therefore, to properly distinguish between these two species, a portion of $\beta$-tubulin gene was also sequenced from these 10 isolates by using $\beta$-tubulin-specific primers $\beta$ TUB-F, 5'-GCTGGGTGGRGCAGCTCAA-3' (Harrow et al. 2010), and T22, 5'TCTGGATGTTGTTGGGAATCC-3' (O'Donnell and Cigelnik 1997). Both $\beta$-tubulin and ITS sequences from these 10 isolates were pairwise analyzed with the ITS and $\beta$-tubulin sequences of reference strains of $F$. acuminatum (AY188923 and AF405457, respectively) and F. tricinctum (U85533 and U85567, respectively) given in The Fusarium Laboratory Manual (Leslie and Summerell 2006), as described in a previous study (Chitrampalam and Nelson, 2014). A PCR was also performed for every purified Fusarium isolate from field samples with the FSSC 11-specific primer set (FSSC11-F and FSSC11-R) to further determine the proportion of FSSC 11 among total Fusarium isolates cultured from 50 soybean samples.
Detection of FSSC 11 from soil. The use of the primer set FSSC11F and FSSC11-R for detecting FSSC 11 directly from soil was also determined. A dry Glyndon loam soil (nonpasteurized), collected from a corn field near Fargo, ND in 2014 was manually infested with FSSC 11 (91-113-3). A spore suspension ( $1 \mathrm{ml}$ at $\left.1 \times 10^{7} \mathrm{spores} / \mathrm{ml}\right)$ prepared from a 3-week-old culture on PDA was added to $10 \mathrm{~g}$ of dry soil, mixed thoroughly, and dried under a laminar flow hood with the blower on for $24 \mathrm{~h}$. Soil with $1 \mathrm{ml}$ of sterilized water served as the noninoculated control. There were three replications. The samples were used either immediately or stored at $-20^{\circ} \mathrm{C}$ for DNA extraction.

DNA was extracted from the infested soil using the MO BIO DNA extraction kit (MO BIO Laboratories, Inc., Carlsbad, CA). The DNA extraction procedure followed the manufacturer's protocol. Two PCR were performed separately for each sample, one with the FSSC11-specific primer set and another with ITS primers (ITS1 and ITS4). The PCR conditions for the FSSC 11-specific primer set and ITS primers were followed as described above on direct amplification from root samples, except the PCR with the FSSC 11-specific primer set, which was performed for 50 cycles.

\section{Results}

FSSC 11-specific primer. Of three primer sets tested, primer set FSSC11-F (5'TCCACTCGGACCCTAAGCAT) and FSSC11-R (5' AAACACTTCCGTGTAGTTGAGG) designed from the RPB2 region was highly specific to FSSC 11 and yielded the expected PCR product of about $900 \mathrm{bp}$ in PCR with DNA from all 22 FSSC 11 isolates tested (Fig. 1; Table 1). However, the same primer set did not yield an amplicon with DNA from all 29 FSSC 5 isolates tested in PCR (Fig. 1; Table 1). The cross reactivity of the primer set FSSC11-F and FSSC11-R with other Fusarium spp. such as FOSC (22 isolates), F. acuminatum (1 isolate), FTSC (19 isolates), FIESC ( 3 isolates), F. graminearum (9 isolates), $F$. proliferatum (3 isolates), $F$. sporotrichioides (4 isolates), and $F$. virguliforme (11 isolates) was also tested, and no amplification was observed with DNA from any of these Fusarium spp. in PCR (Table 1). Furthermore, the same primer set did not produce an amplicon with DNA from soybean (Fig. 1) or four Pythium spp. in PCR (Fig. 1; Table 1). However, every Fusarium and Pythium isolate tested in this study produced an amplicon with ITS primers (ITS1 and ITS4) in PCR (data not shown), suggesting that the previous negative amplification observed for nonFSSC 11 isolates with primer set FSSC11-F and FSSC11-R was exclusively due to primer specificity.

PCR detection limit. A positive PCR amplification was obtained with DNA concentrations of $100 \mathrm{ng}, 10 \mathrm{ng}, 1 \mathrm{ng}$, and $100 \mathrm{pg} / \mathrm{per} 25-\mu \mathrm{l}$ PCR (Fig. 2). However, with the same primer set, no PCR amplification was observed with DNA concentrations of $\leq 10 \mathrm{pg}$ of DNA per 25- $\mu$ l PCR (Fig. 2). The FSSC11-F and FSSC11-R also successfully detected FSSC 11 from the DNA mixture containing soybean DNA at 20 and $200 \mathrm{ng}$ per 25- $\mu$ l PCR (Supplementary Fig. S2). However, the primer set failed to detect FSSC 11 in the presence of soybean DNA at $\geq 2,000 \mathrm{ng}$ per $25-\mu \mathrm{l}$ PCR.

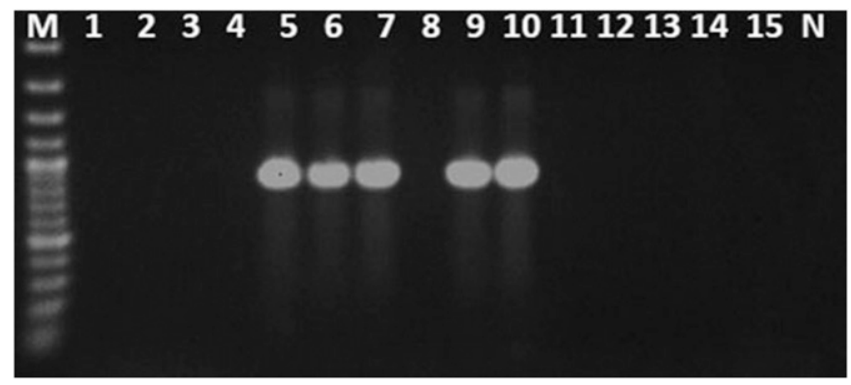

Fig. 1. Specificity of the primer set FSSC11-F and FSSC11-R to Fusarium solani species complex (FSSC) 11 in polymerase chain reaction. Lanes 1, 2, 3, 4, and 8 are FSSC 5 isolates 91-47-3, 91-79-1, 91-85-3, 91-104-2, and 95-5-1, respectively. Lanes 5, 6, 7, 9, and 10 are FSSC 11 isolates 91-112-10, 91-74-3, 91-113-3, SVY$215-1$, and SVY-386-1, respectively. Lanes $11,12,13,14$, and 15 are $F$. oxysporum species complex-SVY-134-1, F. oxysporum species complex-SVY-106-1, F. acuminatum, F. tricinctum species complex, and soybean, respectively. $\mathrm{M}$ and $\mathrm{N}$ are 100-bp marker and negative water control, respectively. 
Detection of FSSC 11 in the presence of FSSC 5 and other Fusarium spp. The PCR assay conducted to determine the efficiency of FSSC11-F and FSSC11-R in detecting FSSC 11 in the background of other Fusarium spp. revealed that the primer set FSSC11-F and FSSC11-R was very efficient in detecting the FSSC 11 from mixed DNA samples. The primer set successfully produced an amplicon specific to FSSC 11 with every DNA mixture tested containing FSSC 11 such as FSSC 11 + FSSC 5, FSSC 11 + FOSC, FSSC 11 + FTSC, FSSC 11 + soybean, and FSSC $11+$ FSSC 5 + FOSC + FTSC + soybean in PCR (Fig. 3). However, the same primer set did not produce amplicons with pure DNA from either FSSC 5, FOSC, FTSC, or soybean in PCR, indicating that the positive amplifications observed with the above five DNA combinations tested were exclusively from the DNA of FSSC 11 (Fig. 3).

Detection of FSSC 11 from soybean roots inoculated with FSSC 11. All four FSSC 11 isolates tested (91-113-3, 91-112-10, SVY-215-1, and SVY-386-1) produced root lesions on soybean.

Table 1. Fusarium and Pythium spp. included in polymerase chain reaction (PCR) amplification with Fusarium solani species complex (FSSC) 11specific primer set and their results

\begin{tabular}{lcc}
\hline Species tested & $\begin{array}{c}\text { Number of } \\
\text { isolates tested }\end{array}$ & $\begin{array}{c}\text { PCR amplification with } \\
\text { FSSC 11-specific primer }\end{array}$ \\
\hline FSSC 11 & 22 & + \\
FSSC 5 & 29 & - \\
F. virguliforme & 11 & - \\
F. oxysporum species & 22 & - \\
$\quad$ complex & 1 & - \\
F. acuminatum & 19 & - \\
F. tricinctum species & & - \\
$\quad$ complex & 3 & - \\
F. incarnatum-equiseti & & - \\
$\quad$ species complex & 9 & - \\
F. graminearum & 3 & - \\
F. proliferatum & 4 & - \\
F. sporotrichioides & 4 & - \\
Pythium spp. & 1 & \\
Soybean (Glycine max) & & \\
\hline
\end{tabular}

a Symbols: + and - indicate positive and negative amplification, respectively.

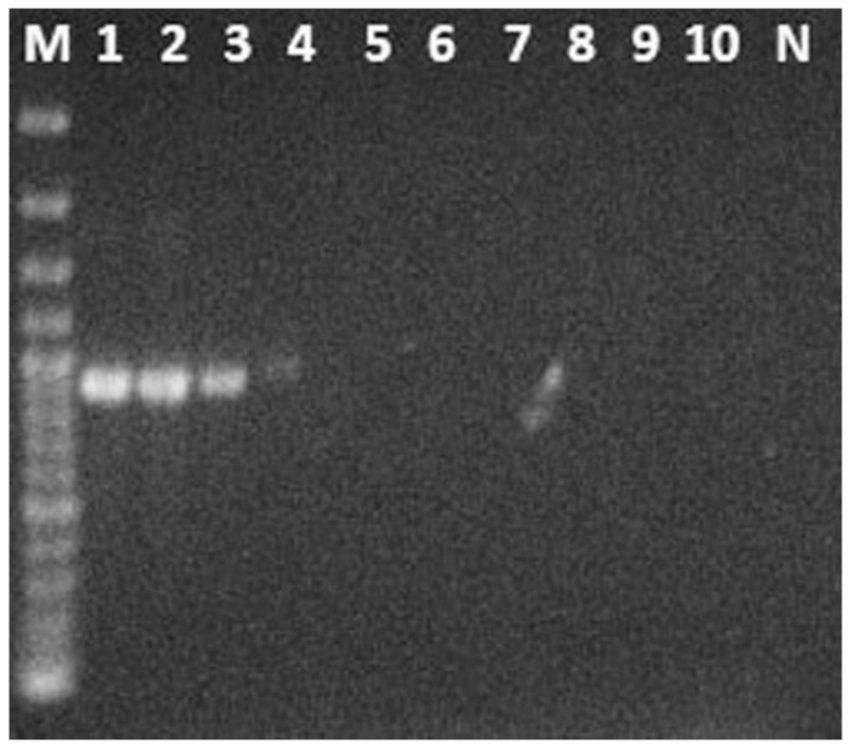

Fig. 2. Determination of DNA concentration limit for primer set FSSC11-F and FSSC11-R to detect Fusarium solani species complex (FSSC) 11 in polymerase chain reaction (PCR). PCR was performed in $25-\mu$ l reactions with nine different concentrations of FSSC 11 DNA. Lanes 1 to 9 are $100 \mathrm{ng}, 10 \mathrm{ng}, 1 \mathrm{ng}, 100$ pg, 10 pg, $1 \mathrm{pg}, 100 \mathrm{fg}, 10 \mathrm{fg}$, and $1 \mathrm{fg}$ of DNA, respectively, per $25-\mu \mathrm{l}$ reaction. $\mathrm{M}$ and $\mathrm{N}$ are 100-bp DNA marker and negative control, respectively.
DNA extracted from roots of each plant infected with an isolate produced an amplicon specific for FSSC 11 in PCR with FSSC 11-specific primers (Supplementary Fig. S3). However, no amplification was observed with DNA from roots of noninoculated control plants in PCR with FSSC 11-specific primers.

Detection of FSSC 11 from field samples using FSSC11-F and FSSC11-R. DNA was extracted from roots of 50 soybean plants from five fields (10 plants/field) and tested for FSSC 11 with FSSC11-F and FSSC11-R in PCR. No amplification was observed with DNA from any of the 20 plants from fields 1 and 4 in PCR. However, there was a positive amplification with DNA from one plant each from fields 2, 3, and 5. Data from field 3 is shown in Figure 4. Sequencing of these PCR products further confirmed their identity to FSSC 11.

Fusarium spp. from field samples. In total, 41 Fusarium isolates were cultured from 50 root samples from five fields; $9,9,9,6$, and 8 isolates from fields 1, 2, 3, 4, and 5, respectively (Tables 2; Supplementary Table S2). Four Fusarium spp. (FOSC, FTSC, FSSC, and FIESC) were identified among the isolates (Table 2). FOSC, FSSC,

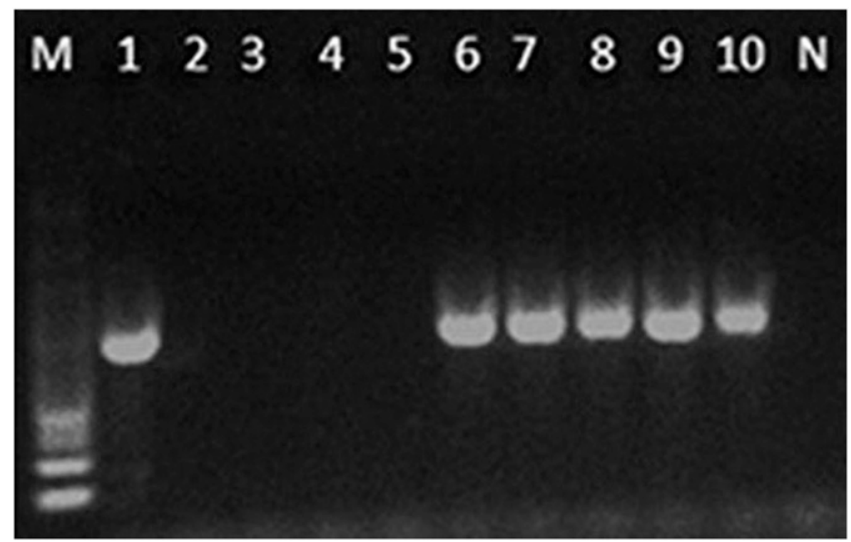

Fig. 3. Efficiency of primer set FSSC11-F and FSSC11-R to detect Fusarium solani species complex (FSSC) 11 in the presence of other Fusarium spp. A series of polymerase chain reactions was performed in $25-\mu$ l reactions with different combinations of DNA from different Fusarium spp. Lane 1: FSSC $11(20 \mathrm{ng})$, lane 2: FSSC 5 (20 ng), lane 3: F. oxysporum species complex (FOSC, $20 \mathrm{ng}$ ), lane 4: F. tricinctum species complex (FTSC, $20 \mathrm{ng}$ ), lane 5 : soybean $(20 \mathrm{ng})$, lane 6 : FSSC 11 (10 ng) + FSSC 5 (10 ng), 7 lane: FSSC 11 (10 ng) + FOSC (10 ng), lane 8: FSSC $11(10 \mathrm{ng})+$ FTSC (10 ng), lane 9: FSSC $11(10 \mathrm{ng})+$ soybean (10 ng) lane 10: FSSC $11(10 \mathrm{ng})+$ FSSC 5 (10 ng) + FOSC (10 ng) + FTSC (10 ng) + soybean (10 ng). Lanes $\mathrm{M}$ and $\mathrm{N}$ are 100-bp DNA marker and negative control respectively.

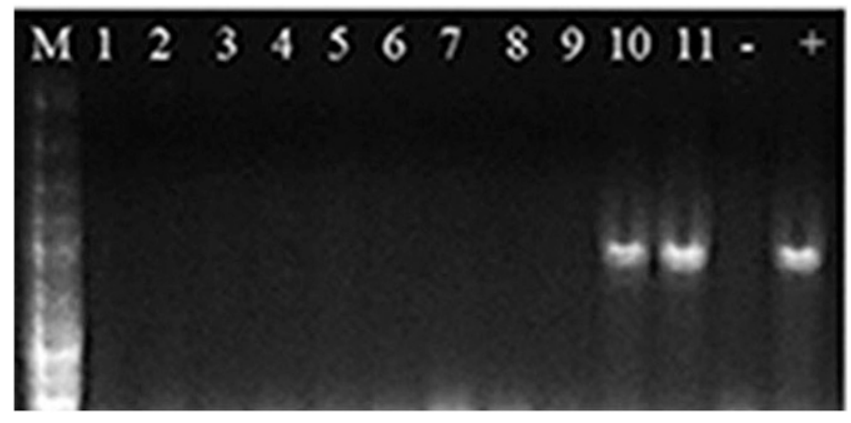

Fig. 4. Polymerase chain reaction (PCR) screening of field samples for Fusarium solani species complex (FSSC) 11 using primer set FSSC11-F and FSSC11-R. DNA was extracted directly from soybean roots collected from the field and used in PCR with FSSC 11-specific primers. On the gel, lanes 1 to 10: DNA from roots of 10 soybean plants from field 3 , and lane 11: DNA from roots artificially infected with FSSC 11 under controlled conditions. Symbols: - and + indicate negative and positive control (FSSC 11), respectively. Note that sample 10 from field 3 was positive for FSSC 11 
and FIESC species were unambiguously identified using NCBI and Fusarium ID databases. However, identification of FTSC with NCBI GenBank and Fusarium ID databases was confusing, and both databases revealed 99 to $100 \%$ identity to both FTSC and F. acuminatum. Nevertheless, the pairwise analysis of ITS and $\beta$-tubulin sequences from putative FTSC isolates with reference sequences of $F$. tricinctum and $F$. acuminatum given in The Fusarium Laboratory Manual (Leslie and Summerell 2006) successfully identified our isolates as FTSC with 96 to $100 \%$ identity for both $\beta$-tubulin and ITS sequences. FOSC was the most predominant species and comprised $44 \%$ of isolates collected, while $27 \%$ of the isolates were identified as FTSC. FSSC and FIESC were identified in 24 and 5\% of isolates collected, respectively. Within the FSSC, two phylogenetic species, FSSC 5 (with 8 isolates) and FSSC 11 (with 3 isolates), were identified (Table 2). FOSC and FTSC were isolated from all five fields sampled. In contrast, FSSC 5, FSSC 11, and FIESC were isolated from 4, 3, and 2 fields, respectively (Table 2). PCR was also performed with DNA from all 41 pure cultured Fusarium isolates with the FSSC 11-specific primer set FSSC11-F and FSSC11-R and a positive amplification was observed only with three FSSC 11 isolates (Fig. 5).

Detection of FSSC 11 from soil. The primer set FSSC11-F and FSSC11-R successfully detected FSSC 11 from field soil manually infested with FSSC 11 (91-113-3). FSSC 11-specific bands were observed with DNA from all three replicated soil samples infested with FSSC 11 in PCR with primers FSSC11-F and FSSC11-R. However, no PCR amplification was observed with DNA from all three replicated noninfested soil samples with FSSC11-F and FSSC11-R. With ITS primers (ITS1 and ITS4), DNA from every sample, including the noninfested control, produced an amplicon in PCR (Supplementary Fig. S4).

\section{Discussion}

A recent study revealed the predominant association of two phylogenetic species, FSSC 5 and FSSC 11, of the FSSC with soybean roots in the north-central United States (Chitrampalam and Nelson 2016). Of the two species, FSSC 11 was identified as the primary FSSC species causing root rot in soybean in that area, whereas FSSC 5 was nonpathogenic or weakly pathogenic on soybean. Furthermore, FSSC 11 from soybean also caused root rot in dry bean, lentil, and pea (Chitrampalam and Nelson 2016), highlighting the threat of FSSC 11 to soybean and pulse production in the north-central United States. Currently, no rapid and accurate method is available to detect and distinguish FSSC 11 from FSSC 5, other Fusarium spp., and Pythium spp. associated with soybean roots. This research successfully developed a PCR-based assay to specifically detect FSSC 11 from soybean. The $R P B 2$ gene was successfully used in previous studies to determine species diversity within the FSSC (Nalim et al. 2011; O'Donnell et al. 2008; Zhang et al. 2006). Therefore, the $R P B 2$ region was used in the current study to design primers specific for FSSC 11. The primer set FSSC11-F and FSSC11-R designed in this study was highly specific for FSSC 11 and yielded the expected amplicon with DNA from every FSSC 11 isolate tested in PCR, emphasizing its accuracy in identifying FSSC 11. However, with the same primer set, no amplification was observed in PCR with DNA from FSSC 5 and seven other Fusarium spp.: FTSC, F. acuminatum, FOSC, FIESC, $F$. graminearum, $F$. virguliforme, and $F$. proliferatum. No PCR amplification was also observed with DNA from Pythium spp. and soybean root tissue. These negative PCR amplifications of FSSC 5, other Fusarium spp., and Pythium spp. with FSSC11-F and FSSC11-R highlighted the exceptional specificity of this primer set to FSSC 11. Furthermore, this primer set also detected FSSC 11 from PCR samples containing the FSSC 11 DNA concentration as low as $100 \mathrm{pg}$, and this detection limit can be further enhanced either by adjusting PCR conditions or incorporating an additional nested PCR, as suggested in previous studies (Fan et al. 2015; Li and Hartman 2003). For example, with the inclusion of nested PCR, the sensitivity of the PCR assay in detecting $F$. virguliforme from field samples was increased 1,000-fold (Li and Hartman 2003).
The primer set FSSC11-F and FSSC11-R also efficiently detected FSSC 11 directly from soybean roots independent of isolation. For example, in a greenhouse experiment, four FSSC 11 isolates were inoculated individually on soybean, and the roots were collected 5 weeks after inoculation. All four isolates produced lesion on the roots and, likewise, the DNA extracted directly from roots infected by all four isolates were also positive for FSSC 11 in PCR with FSSC11-F and FSSC11-R, further highlighting the consistency of the primer set across the FSSC 11 isolates. These positive detections of FSSC 11 from impure DNA containing the DNA of several other Fusarium spp. and soybean and also directly from soybean roots infected with FSSC 11 in PCR suggested that the primer set FSSC11-F and FSSC11-R would be very useful to specifically detect FSSC 11 directly from roots collected from soybean fields.

Results were consistent from both the culture-based assay and the culture-independent PCR-based assay with FSSC 11-specific primers performed to determine the prevalence of FSSC 11 in five soybean production fields in North Dakota. With culture-based assays,

Table 2. Fusarium spp. associated with soybean roots from five fields in North Dakota in 2015

\begin{tabular}{lcccccc}
\hline Field $^{\mathbf{b}}$ & Total isolates $^{\mathbf{c}}$ & FOSC & FSSC 5 & FSSC 11 & FTSC & FIESC \\
\hline 1 & 9 & 2 & 1 & 0 & 5 & 1 \\
2 & 9 & 3 & 4 & 1 & 1 & 0 \\
3 & 9 & 7 & 0 & 1 & 1 & 0 \\
4 & 6 & 3 & 2 & 0 & 1 & 0 \\
5 & 8 & 3 & 1 & 1 & 2 & 1 \\
Total & 41 & $44 \%$ & $20 \%$ & $7 \%$ & $24 \%$ & $5 \%$ \\
\hline
\end{tabular}

${ }^{\text {a }}$ FSSC $=$ Fusarium solani species complex, FOSC $=F$. oxysporum species complex, FTSC $=F$. tricinctum species complex, and FIESC $=F$. incarnatum equiseti species complex.

$\mathrm{b}$ Ten seedlings showing symptoms of root rot were collected randomly from each field and assayed for Fusarium spp. Two root pieces from each sample were plated on Nash \& Snider media, and emerging Fusarium spp. were isolated, pure cultured and identified by DNA sequencing method.

c Total number of isolates isolated.

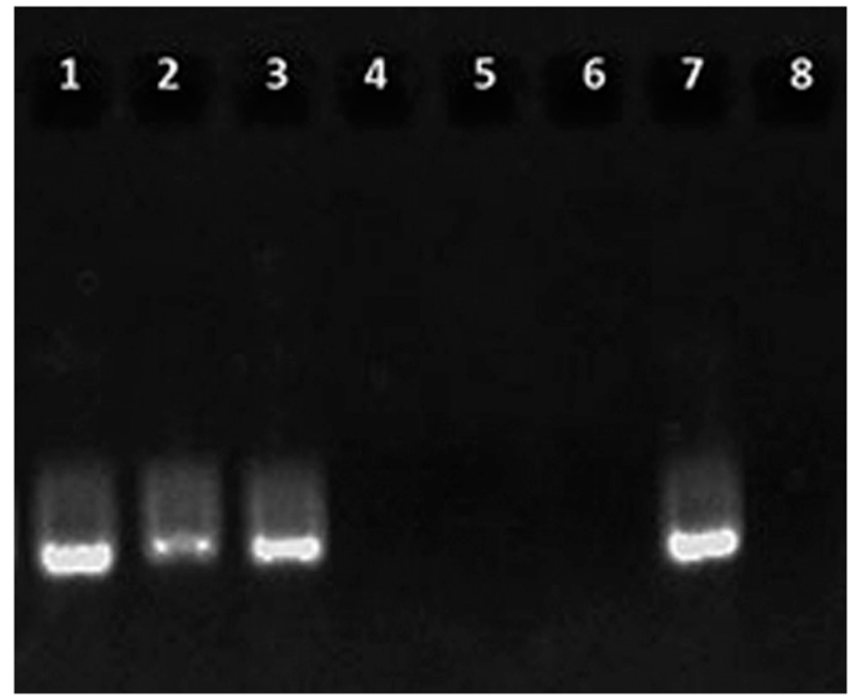

Fig. 5. Polymerase chain reaction (PCR) screening of Fusarium isolates pure cultured from soybean roots collected from five fields in 2015 with primer set FSSC11-F and FSSC11-R to identify Fusarium solani species complex (FSSC) 11. In total, 41 isolates were cultured from soybean roots from five fields. PCR was performed on each isolate with FSSC 11-specific primers. Only representative isolates are listed in the gel. Lanes 1 to 3 are FSSC 11 isolates and lanes 4, 5, and 6 are $F$. tricinctum species complex, F. oxysporum species complex, and F. incarnatumequiseti complex, respectively. Lanes 7 and 8 are positive control (FSSC11; 91113-3) and negative control, respectively. 
41 Fusarium isolates were isolated from 50 plants, and only 3 isolates, each 1 from a different field, were FSSC 11. Likewise, PCR performed with DNA extracted directly from root samples with FSSC11-F and FSSC11-R also revealed the positive amplification for FSSC 11 with three samples, one sample each from the same three fields, as with the culture-based assay. Most of the Fusarium isolates cultured from soybean roots were FOSC (44\% of isolates), FTSC (24\%), and FSSC $5(20 \%)$. These results clearly suggested that the primer set FSSC11-F and FSSC11-R designed in this study was highly specific to FSSC 11 and could be useful to unambiguously identify root rot caused by FSSC 11 and also to determine the prevalence of FSSC 11 in soybean fields.

The primer set FSSC11-F and FSSC11-R also successfully detected FSSC 11 from soil artificially infested with FSSC 11. However, only one spore concentration, $10^{6}$ macroconidia/g of soil, was used in this study to determine the efficiency of the primer to detect FSSC 11 from soil. In future research, additional spore concentrations between 10 and $10^{6}$ macroconidia/g of soil should be investigated to optimize the detection limit for FSSC11-F and FSSC11-R to specifically detect FSSC 11 from soil. Furthermore, it is also worth investigating the compatibility of the FSSC 11-specific primer set with other Fusarium spp.specific primers in the literature (Chitrampalam and Nelson 2016; Li and Hartman 2003) for concurrent detection of multiple Fusaria in a single PCR assay. qPCR is more advanced than conventional PCR, and it not only saves the time and steps associated with gel electrophoresis but also more precisely detects and quantifies the target. However, the potential use of the FSSC 11-specific primer set designed in this study in a qPCR assay is limited because of the size of the amplicon. Normally, for a qPCR assay, an amplicon size of $<200 \mathrm{bp}$ is recommended, but the amplicon size obtained with FSSC11-F and FSSC11-R for FSSC 11 was about 900 bp. Nevertheless, attempts have also been successfully made to amplify a PCR product of $>1 \mathrm{~kb}$ in $\mathrm{qPCR}$ by modifying the qPCR parameters and conditions (Grunenwald and Kramer 2004). Therefore, the possibility of using the FSSC 11-specific primer set in a qPCR assay is still open for further investigation. However, one big advantage of the PCR-based approach over $\mathrm{qPCR}$ is that the PCR product from conventional PCR can easily be sequenced to further confirm the target-specific amplification, and that sequence can also be used for further study such as a phylogenetic study.

Results from field sampling also revealed important information on the distribution of Fusarium spp. in the sampled soybean fields in North Dakota. Three Fusarium spp.-FOSC, FSSC, and FTSC-were the predominant species associated with soybean roots collected from five fields in 2015 , with 44,27 , and $24 \%$ of total isolates cultured from field samples, respectively. They were isolated from all five fields sampled. Furthermore, within the FSSC, two species, FSSC 5 and FSSC 11, were identified, with FSSC 5 as the most predominant species, with eight isolates, followed by FSSC 11, with three isolates. This result is consistent with a previous study which also revealed the predominant association of FSSC 5 (60\%) compared with FSSC11 (34\%) with soybean roots in the north-central United States (Chitrampalam and Nelson 2016).

The predominant association of FOSC with soybean roots in the sampled fields is consistent with results from several previous surveys conducted in the Red River Valley and also other soybeanproducing states in the United States (Diaz Arias et al. 2013a,b; Nelson and Windels 1992). The role of FOSC in causing seedling disease and root rot in soybean is well established in soybeanproducing states such as Iowa (Diaz Arias et al. 2013a,b; Ellis et al. 2014), Virginia (Farias and Griffin 1989), Minnesota (Bienapfl 2011), and Illinois (Killebrew et al. 1993) but its significance in soybean production in North Dakota is not well understood despite its predominant association with soybean roots. Furthermore, FOSC consists of several phylogenetic species (Ellis et al. 2014), and the information on the FOSC species diversity associated with soybean roots and the primary phylogenetic species potentially causing damage in soybean is unknown in North Dakota, which warrants a further detailed study. Members of the FTSC were also found to be commonly associated with soybean roots in the sampled fields in North Dakota, and 10 of 41 isolates cultured from 50 samples from five fields were members of FTSC. Association of FTSC with soybean roots has also been reported in previous studies (Chitrampalam and Nelson 2014; Diaz Arias et al. 2013a; Meyer et al. 2010; Zhang et al. 2010).

In conclusion, the primer set FSSC11-F and FSSC11-R is highly specific to FSSC 11, and not only differentiates FSSC 11 from FSSC 5 and other Fusarium spp. but also identifies FSSC 11 directly from soybean roots without the need to verify using other methods. This primer set would be useful in a field survey to determine the prevalence of FSSC 11 in soybean roots and field soil plus aid in-depth studies of the biology of Fusarium root rot in soybean.

\section{Acknowledgments}

We thank the North Central Soybean Research Program and the United Soybean Board for supporting this research and T. Christianson and H. Yan for their help in collecting the samples from field. This work is supported by the United States Department of Agriculture National Institute of Food and Agriculture Hatch Project ND02226.

\section{Literature Cited}

Bienapfl, J. C. 2011. Fusarium and Phytophthora species associated with root rot of soybean (Glycine max). Ph.D. thesis, University of Minnesota.

Chen, W., Gray, L. E., Kurle, J. E., and Grau, C. R. 1999. Specific detection of Phialophora gregata and Plectosporium tabacinum in infected soybean plants using polymerase chain reaction. Mol. Ecol. 8:871-877.

Chitrampalam, P., and Nelson, B. D., Jr. 2014. Effect of Fusarium tricinctum on growth of soybean and a molecular-based method of identification. Online publication. Plant Health Prog. doi.org/10.1094/PHP-RS-14-0014

Chitrampalam, P., and Nelson, B. D., Jr. 2016. Multilocus phylogeny reveals an association of agriculturally important Fusarium solani species complex (FSSC) 11, and clinically important FSSC 5 and FSSC $3+4$ with soybean roots in the north central United States. Antonie Leeuwenhoek 109 335-347.

Diaz Arias, M. M., Leandro, L. F., and Munkvold, G. P. 2013a. Aggressiveness of Fusarium species and impact of root infection on growth and yield of soybeans. Phytopathology 103:822-832.

Diaz Arias, M. M., Munkvold, G. P., Ellis, M. L., and Leandro, L. F. 2013b. Distribution and frequency of Fusarium species associated with soybean roots in Iowa. Plant Dis. 97:1557-1562.

Ellis, M. L., Cruz Jimenez, D. R., Leandro, L. F., and Munkvold, G. P. 2014. Genotypic and phenotypic characterization of fungi in the Fusarium oxysporum species complex from soybean roots. Phytopathology 104:1329-1339.

Fan, X., Zhang, J., Yang, L., Wu, M., Chen, W., and Li, G. 2015. Development of PCR-based assay for detecting and differentiating three species of Botrytis infecting broad bean. Phytopathology 99:691-698.

Farias, G. M., and Griffin, G. J. 1989. Roles of Fusarium oxysporum and F. solani in Essex Disease of soybean in Virginia. Plant Dis. 73:38-42.

Grunenwald, H., and Kramer, K. 2004. Cloning real time PCR product; does SYBR green I dye interfere? Epicentre Forum 11:17-19.

Harrow, S. A., Farrokhi-Nejad, R., Pitman, A. R., Scott, I. A. W., Bentley, A., Hide, C., and Cromey, M. G. 2010. Characterization of New Zealand Fusarium populations using a polyphasic approach differentiates the $F$. avenaceum/ $F$. acuminatum/ F. tricinctum species complex in cereal and grassland systems. Fungal Biol. 114: 293-311.

Hong, S., Kang, M. R., Cho, E., Kim, H., and Yun, S. 2010. Specific PCR detection of four quarantine species in Korea. Plant Pathol. J. 26:409-416.

Killebrew, J. F., Roy, K. W., and Abney, T. S. 1993. Fusaria and other fungi on soybean seedlings and roots of older plants and interrelationship among fungi, symptoms, and soil characteristics. Can. J. Plant Pathol. 15:139-146.

Koenning, S. R., and Wrather, J. A. 2010. Suppression of soybean yield potential in the continental United States by plant diseases from 2006 to 2009 . Online publication. Plant Health Prog. doi.org/10.1094/PHP-2010-1122-01-RS

Leslie, J. F., and Summerell, B. A. 2006. The Fusarium Laboratory Manual. Blackwell Press, Oxford. doi.org/10.1002/9780470278376

Li, S., and Hartman, G. L. 2003. Molecular detection of Fusarium solani f. sp. glycines in soybean roots and soil. Plant Pathol. 52:74-83.

Lievens, B., and Thomma, B. P. H. J. 2005. Recent developments in pathogen detection arrays: Implications for fungal plant pathogens and use in practice. Phytopathology 95:1374-1380.

Meyer, P. W., Clancey, M. S., Brose, I. E., and Kurle, J. E. 2010. First report of Fusarium root rot caused by Fusarium tricinctum in Minnesota. (Abstr.). Phytopathology 100:S188.

Nalim, A. F., Samuels, J. G., Wijesundera, L. R., and Geiser, M. D. 2011. New species from the Fusarium solani species complex derived from perithecia and soil in the old world tropics. Mycologia 103:1302-1330.

Nash, S. M., and Snyder, W. C. 1962. Quantitative estimations by plate counts of propagules of the bean root rot Fusarium in field soils. Phytopathology 52: 567-572. 
Nelson, B. D., Hansen, J. M., Windels, C. E., and Helms, T. C. 1997. Reaction of soybean cultivars to isolates of Fusarium solani from the Red River Valley. Plant Dis. 81:664-668.

Nelson, B. D., and Windels, C. E. 1992. Pathogenicity of Fusarium spp., on soybean in the Red River Valley. (Abstr.). Phytopathology 82:994.

O'Donnell, K. 2000. Molecular phylogeny of the Nectria haematococca-Fusarium solani species complex. Mycologia 92:919-938.

O'Donnell, K., and Cigelnik, E. 1997. Two divergent intragenic rDNA ITS2 types within a monophyletic lineage of the fungus Fusarium are nonorthologous. Mol. Phylogenet. Evol. 7:103-116.

O’Donnell, K., Sutton, D. A., Fothergill, A., McCarthy, D., Rinaldi, M. G., Brandt, M. E., Zhang, N., and Geiser, D. M. 2008. Molecular phylogenetic diversity, multilocus haplotype nomenclature, and in vitro antifungal resistance within the Fusarium solani species complex. J. Clin. Microbiol. $46: 2477-2490$.
Rupe, J., Rothrock, C., and Avanzato, M. 2010. Characterization of Pythium and Fusarium species associated with soybean seeds and seedlings. (Abstr.). Phytopathology 100:S111.

Wang, C., Lin, Y., and Chung, W. 2013. Modified primers for the identification of nonpathogenic Fusarium oxysporum isolates that have biological control potential against Fusarium wilt of cucumber in Taiwan. PLoS One 8:e65093.

Zhang, J. X., Xue, A. G., Zhang, H. J., Nagasawa, A. E., and Tambong, J. T. 2010 Response of soybean cultivars to root rot caused by Fusarium species. Can. J. Plant Sci. 90:767-776.

Zhang, N., O’Donnell, K., Sutton, D. A., Nalim, F. A., Summerbell, R. C., Padhye, A. A., and Geiser, D. M. 2006. Members of the Fusarium solani species complex that cause infections in both humans and plants are common in the environment. J. Clin. Microbiol. 44:2186-2190.

Zitnick-Anderson, K. K., and Nelson, B., Jr. 2015. Identification and pathogenicity of Pythium on soybean in North Dakota. Plant Dis. 99:31-38. 